\title{
Development of a mathematical model of a biomechatronic finger prosthesis as part of a multifunctional prosthetic hand
}

\author{
Aleksey Lysenko ${ }^{1, *}$, Denis Khashev ${ }^{1}$, and Ekaterina Uryanskaya $^{2}$ \\ ${ }^{1}$ Don State Technical University, Robotics resource centre, 344000 Rostov-on-Don, Russia \\ ${ }^{2}$ Don State Technical University, "Robotics and Mechatronics" department, 344000 Rostov-on-Don, Russia
}

\begin{abstract}
A mathematical model of a biomechanical finger prosthesis is proposed, which makes it possible to study its dynamics under the condition of an increased degree of mobility of the structure under consideration. Increased degree of mobility avoids the disadvantages of creating a multifunctional biomechanical hand prosthetic.
\end{abstract}

\section{Introduction}

The development of a fully functioning artificial prosthesis of a hand operating at speeds close to normal human responses and with a force comparable to a physiologically human-like one with real-time control is an urgent task of prosthetics of the upper limbs. Unfortunately, the modern component base and interface technologies are still far from realizing this task. A modern prosthesis can be considered as an instrument, not a replacement of a limb $[1,2,3]$.

The person during the capture makes a new mechanism of the hand, depending on the purpose of the movement, on the nature of the object (size, mass, shape, consistency). The basis for a variety of movements are six types of capture: hook, interdigital, planar, plucked, cylindrical, ball $[4,5,6]$. Having considered a technological process standard for the hand, conditionally it consisting of three phases: compression of the object; holding the object; release of the subject $[7,8,9]$. When carrying out these actions with a natural hand, it is noticed that the greatest efforts are observed in the first phase. Based on the experience of performing typical actions with the use of the hand, the average value of $F=50 \mathrm{~N}$ tension on the joint between the 2 and 3 phalanges of the finger was obtained. This requirement corresponds to a lifting by one finger of a cargo of $5 \mathrm{~kg}$ weight sufficient to perform the basic actions of the natural hand.

\section{Solution of design problems}

In the framework of this paper, the structure of the mechatronic module is proposed (Fig. 1).

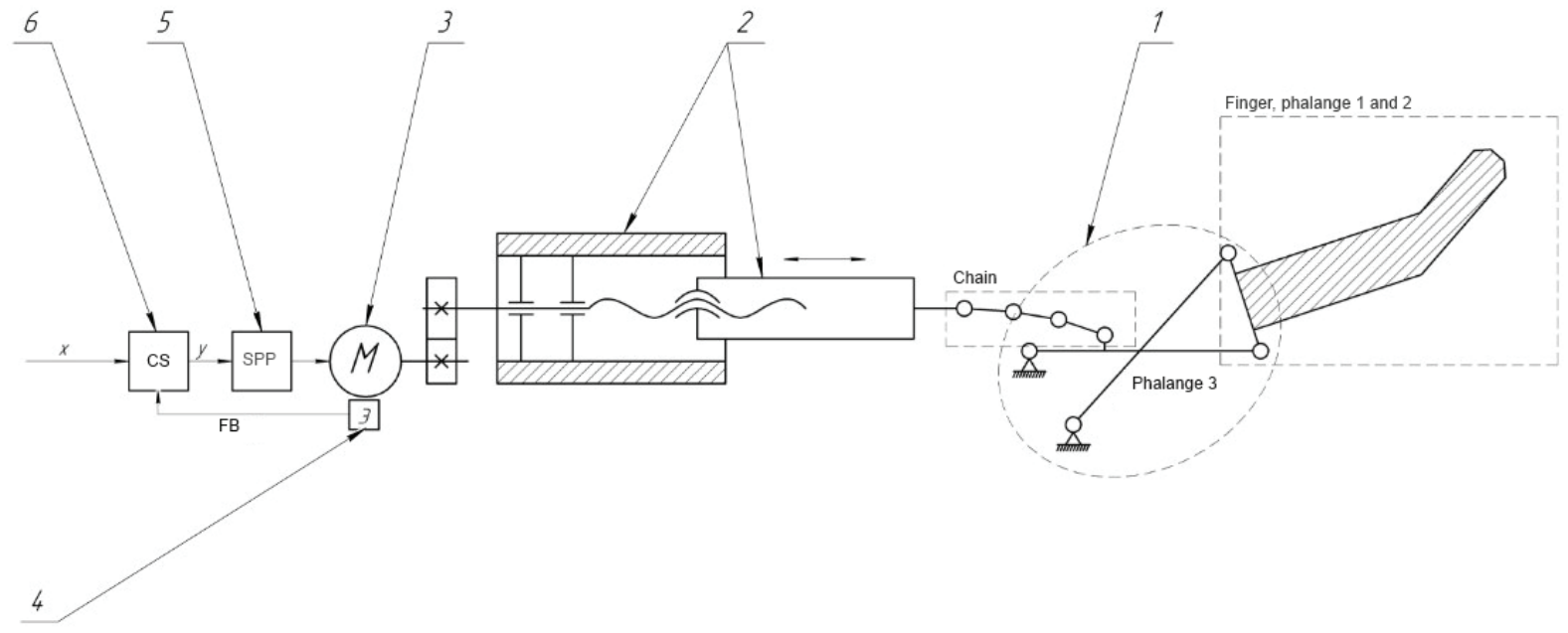

Fig. 1. Structural scheme of the mechatronic module.

1- The lever mechanism of the finger; 2 - Transmission of the screw-nut of sliding; 3 - Micromotor "M"; 4 - the Sensor of speed of rotation of a shaft of the engine "E"; 5 - Driver of the engine (block "SPP" - power semiconductor converters); 6 - SPP control pulse shaping system, and microprocessor control system; 7 - Miointerface (signals "x" from the sensors of the miopotential). 
In the kinetostatic calculation, the method of dividing the kinematic chain of the mechanism into Assurian groups $[10,11]$ is used, which are statically determinable. A calculation of the kinematic chain mobility degree is made according to the Somov-Malyshev formula for spatial mechanisms, the links of which can move in different mutually perpendicular planes [11]:

$$
W=6 n-k p_{i}
$$

where $n$ is the number of moving links;

$k p_{i}$ - the number of 5, 4, 3, 2, 1 class kinematic pairs.

In the considered kinematic scheme, all kinematic pairs are rotational, of which $\mathrm{p}_{3}: 4, \mathrm{p}_{4}: 2$. Substituting the values in formula (1), the degree of mobility is $\mathrm{W}=16$. Often, in similar models, the finger is presented in a simplified form without one kinematic pair of the third class. In this case, $\mathrm{p}_{3}: 3, \mathrm{p}_{4}: 2$, and the degree of mobility is $\mathrm{W}=13$. Thus, the number of possible independent displacements of the model links is significantly reduced, which for the kinematic chain as a whole means a loss of mobility capabilities of $18.75 \%$. The model of the lever mechanism of the finger (Figure 2), compiled in accordance with the chosen design, is considered. Knowing the lengths of the links and their types, a model of the kinematic scheme in Simulink is compiled using the SimMechanics package $[12,13]$.

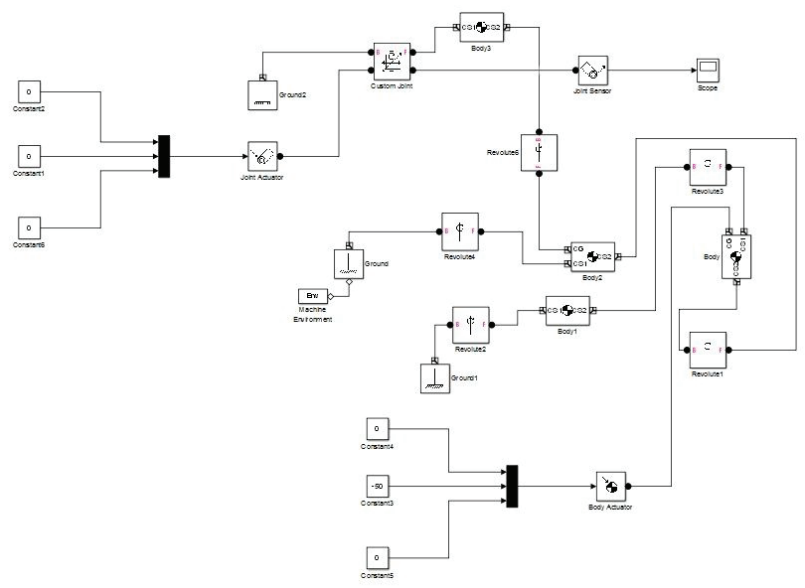

The forces in the mechanical transmissions of a pair of screw-nut and gears are calculated in order to determine the required mechanical power of the engine. Based on the calculations in Table 1 , a $\mathrm{P}=0.14 \mathrm{~W}$ motor with the smallest size and equipped with a reducer was chosen.

The analysis of the continuous-mechanical system and the synthesis of digital regulators for the control object are performed. A block diagram of the finger control system is considered, where in Fig. 3 the main parts of the model are marked: Speed regulator blocks, the task of the input action, the transfer function of the regulator and the block for limiting its output; Current controller blocks, transfer function and feedback factors; Blocks PWT, the generator of a sawtooth signal, an ideal key and the smoothing filter; Blocks DC motor, load problem, transfer functions of the engine.

Table 1. Calculation of engine parameters.

\begin{tabular}{|c|c|c|}
\hline Parameter & Formula & Value \\
\hline $\begin{array}{c}\text { Transmission ratio of } \\
\text { screw-nut } \\
\text { transmission. }\end{array}$ & $\mathrm{u}=\frac{\pi \mathrm{D}}{\mathrm{S}}$ & 22 \\
\hline $\begin{array}{c}\text { Circular force on the } \\
\text { pinion of the screw, } \mathrm{N}\end{array}$ & $\mathrm{F}_{\text {окр1 }}=\frac{\mathrm{F}_{\text {треб }}}{\mathrm{u}}$ & 5,27 \\
\hline $\begin{array}{c}\text { Circular force on the } \\
\text { gear wheel of the } \\
\text { engine, } \mathrm{N}\end{array}$ & $\mathrm{F}_{\text {окр1 }}=\mathrm{u}$ & 3,19 \\
\hline $\begin{array}{c}\text { Torque on the engine, } \\
\text { Nm }\end{array}$ & $\mathrm{M}_{\text {треб }}=\mathrm{F}_{\text {окр2 }} * \frac{\mathrm{D}}{2}$, & 0,011 \\
\hline $\begin{array}{c}\text { Engine speed, rpm } \\
\mathrm{n}=\frac{\mathrm{V}}{\mathrm{S}},\end{array}$ & 120 \\
\hline Engine power, $\mathrm{W}$ & $\mathrm{P}=\frac{\mathrm{Mn}}{9.55}$, & 0.14 \\
\hline
\end{tabular}

Fig. 2. Model of the lever mechanism.

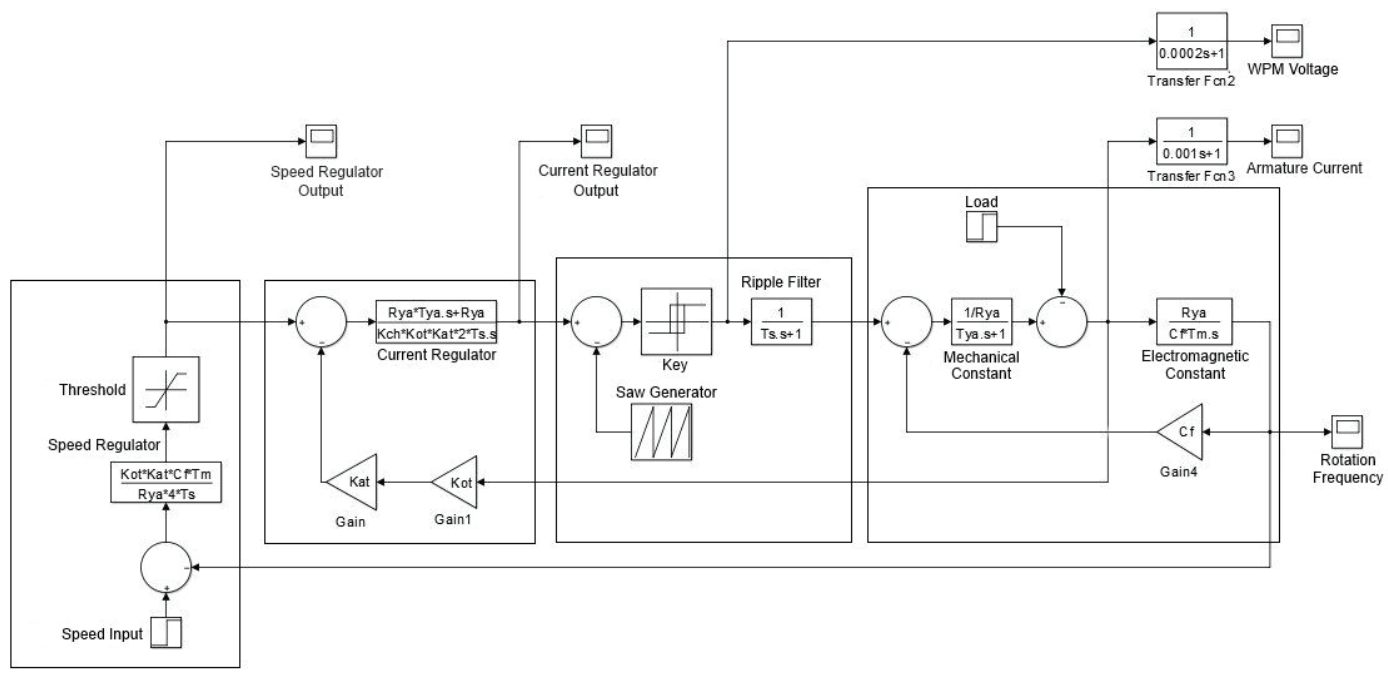

Fig. 3. Structural diagram of the control system. 
The numerical values of the transfer functions of the continuous current and speed regulators, as well as the transfer functions of the selected DC motor are calculated. In order to do so the current feedback coefficient was found using the formulas from Table $2[14,15]$.

Table 2. Value of transfer units and their coefficients.

\begin{tabular}{|c|c|}
\hline Formula & Value \\
\hline $\mathrm{K}_{\text {от }}=\frac{U_{\text {огр }}}{\mathrm{I}_{\mathrm{H}} * K_{\text {aт }}}$ & 13.7 \\
\hline $\mathrm{U}_{\text {огр }}=\mathrm{U}_{\text {ШП }}$ & $2^{16}$ \\
\hline$K_{\text {ат }}$ & $1.986 \mathrm{e}+04$ \\
\hline $\mathrm{U}_{\text {ш }}$ & 1.05 \\
\hline$\kappa_{\mathrm{ш}}=\frac{\mathrm{U}_{\text {ш }}}{\mathrm{U}_{\text {шп }}}$ & $1.602 \mathrm{e}-05$ \\
\hline $\mathrm{cF}=\frac{\mathrm{U}_{\mathrm{H}}-\mathrm{R} * \mathrm{I}_{\mathrm{H}}}{\omega_{\mathrm{H}}}$ & 0.0024 \\
\hline $\mathrm{K}_{\text {оси }}=\frac{\mathrm{N}_{\text {ди }} \mathrm{T}}{2 * \pi}$ & 0.0398 \\
\hline $\begin{array}{l}\mathrm{W}_{\mathrm{pT}}(\mathrm{p}) \\
=\frac{\mathrm{R} *\left(\mathrm{~T}_{\mathrm{a}} * \mathrm{p}+1\right)}{\mathrm{K}_{\mathrm{U}} * \mathrm{~K}_{\mathrm{oT}} * \mathrm{~K}_{\mathrm{aT}} * 2 * \mathrm{~T}_{\mathrm{s}} * \mathrm{p}}\end{array}$ & $\begin{array}{l}\mathrm{W}_{\mathrm{pr}}(\mathrm{p}) \\
=\frac{5.7 *((1.1578 \mathrm{e}-05) * \mathrm{p}+1)}{(1.602 \mathrm{e}-05) * 13.75 *(1.986 \mathrm{e}+04) * 2 * 0.005 * \mathrm{p}}\end{array}$ \\
\hline $\begin{array}{l}\mathrm{W}_{\mathrm{pc}}(\mathrm{p}) \\
=\frac{\mathrm{K}_{\mathrm{oT}} * \mathrm{~K}_{\mathrm{aT}} * \mathrm{cF} * \mathrm{~T}_{\mathrm{m}}}{\mathrm{R} * 4 * \mathrm{~T}_{\mathrm{s}}}\end{array}$ & $\begin{array}{l}\mathrm{W}_{\mathrm{pc}}(\mathrm{p}) \\
=\frac{13.75 *(1.986 \mathrm{e}+04) * 0.0024 * 0.012}{5.7 * 4 * 0.005}\end{array}$ \\
\hline
\end{tabular}

Calculation of the numerical data of the current loop is performed for a filter with a time constant Ts $=0.005 \mathrm{sec}$. The filter is only necessary for the synthesis of the current loop of a continuous subordinate control system.

In the course of the study, the regulator was reduced to a discrete form. As a result, during the modeling of electromechanical mechanical system of the prosthesis it was revealed that when the period of sampling of the regulator changes, the simulated model loses its stability when the sampling period is more than 0.00001 seconds.

\section{Conclusion}

Having examined the graphs of the simulation results in Fig. 4, with given input impacts of angular velocity of 500 $\mathrm{rad} / \mathrm{s}$, at the time $\mathrm{t}=0.4 \mathrm{sec}$, and at the time $\mathrm{t}=1.4 \mathrm{sec}$ the load applied to the motor shaft is $0.3 \mathrm{Nm}$, it is concluded that the mathematical model of the control system is synthesized correctly, the output values of the regulators do not exceed the permissible limits, the control time is close to the constant time of the motor itself. a)

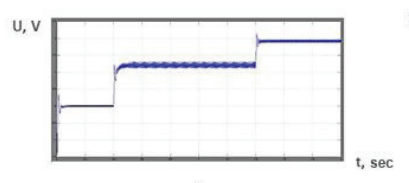

c)

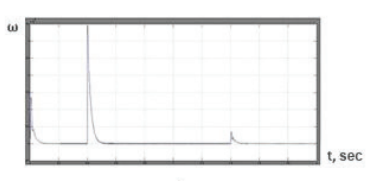

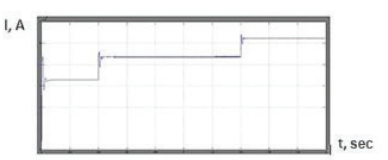

b)

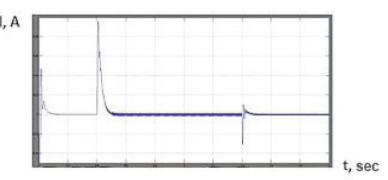

d)

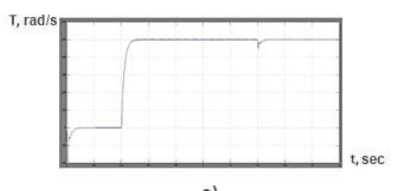

e)

Fig. 4. The graphs of the control system investigation: (a) the output of the speed controller, the discrete code $0 \ldots 65535$, (b) the current controller output, the discrete code $0 \ldots 65535$, (c) the average PWT voltage, (d) the armature current, (e) the shaft speed, $\mathrm{rad} / \mathrm{s}$

\section{References}

1. D. Craig, Introduction to Robotics. Mechanics and management, Publishing Institute of Computer Research, p.564 (2013)

2. R. H. Taylor, Proc. IEEE, Spec. iss. "Medical Robotics", 94, No.9, 1652-1664 (2006)

3. G.V. Savrasov, Biomed. Radioelectronics, 10, 42-46 (2007)

4. Bone-Surgery, available at: http://bonesurgery.ru/view/kist_kak_organ/

5. M.C. Carrozza, G. Cappiello, S. Micera, B. B. Edin, L. Beccai, C. Cipriani, Biol Cybern 95, 629-644 (2006)

6. Grabcad, available at: https://grabcad.com/library/bionic-hand-concept-1

7. Enciklopediya Tehniki, available at: http://enciklopediya-tehniki.ru/promyshlennost-nar/rychazhnyy-mehanizm.html

8. B.I. Glotov, Power calculation of plane latch mechanism. Methodical instructions for the course project on the theory of mechanisms and machines for students, Barnaul (2000)

9. V.D. Britsky, G.B. Zamoruev, M.A. Nozdrin, Study of the lever mechanism. Tutorial, SPb: SPbSU ITMO, p.30 (2007)

10. I.I. Artobolevsky, The theory of machines and mechanisms. Textbook for universities, 4 th ed., p. 640 (1988)

11. I.I. Borisov, S.S. Reznikov, The Week of Science of SPbSPU. Materials of the sci-pract. conf. with int. particip. Pt 1., 85-88 (2014)

12. I.I. Borisov, S.V. Krivosheev, S.S. Reznikov, Collection of reports theses of the young scientists congress, 2, 351-352 (2014) 
13. I.I. Borisov, S.V. Krivosheev, S.S. Reznikov, Almanac of scientific works of young scientists at the University ITMO, 55-58 (2014)

14. V.S. Shcherbakov, M.S. Korytov, A.A. Ruppel Modeling and visualization of movement of mechanical systems in Matlab, (SibAD, Omsk, 2007)

15. P.N. Kuninin, The study of the microprocessor control device with pulse-width converter by means of Matlab: Laboratory practical. 